\title{
Influence of Employment Status of Housewives on Sexual Violence Experienced by Married Women in Ekiti State
}

\author{
Grace Funmilayo Olusegun \\ Department of Guidance and Counselling, Faculty of Education, \\ Ekiti State University, Ado Ekiti, Nigeria
}

\begin{abstract}
This study investigated the influence of employment status of housewives on sexual violence experienced by married women in EkitiState, Nigeria. The population consisted of all married women in Ekiti-State. The sample consisted of 60 married women randomly selected from six Local Governments Areas. The strata recognised age, religion, education levels, employment status, duration of marriage, and number of children. An instrument titled "Sexual Violence within Marriage Questionnaire" was used. The reliability coefficient of the instrument was estimated at 0.75 using Pearson Product Moment Correlation. Data collected were analysed using student t-test and tested at 0.05 level of significance. The result revealed that housewives that are sexually coerced suffered physical, emotional, social, psychology and health consequences. There is also a significant different in the sexual violence experienced by working and full housewives. Based on the findings, it was recommended that people should have the knowledge that sexual violence within marriage is a crime and that husbands could be prosecuted. Full house wives should engage in a business to avoid incessant sexual demand from their husband. This research is important because it uncovered the consequences of sexual violence within marriage and the barriers of being a full housewife in Ekiti State, Nigeria.
\end{abstract}

\section{Introduction}

Sexual violence encompasses the sum total of a person's sexual behaviour that is unwanted. It ranges from touching to any other sexual nature that is unwanted, an act of violence against the victim's will. The victim is forced to submit to unwanted sexual acts that could humiliate someone through intimidation, authority, anger, verbal threat, profane language, physical violence, force to overpower the victim to achieve their intention. This act could result to chronic physical and psychological conditions, such as physical injury, myriad of health consequences, fear, lack of freedom, lack of concentration at work, depression, drug abuse, women inability to bring up their children in a proper way, divorce and so on. There is need to address this unruly act of men against women so as to build a healthy home.

Studies on sexual behaviour are still neglected. However, until recently, the epidemic of HIV/AIDS and other Sexually Transmitted Infections (STIs) made it popular as part of control programme to stem further spread, issues on it are just springing up. A salient aspect of it will be addressed in this study. "Sexual Violence within Marriage (SVWM)", is one of the most underreported crimes, and this makes it difficult to document due to difficulties in collecting required information. Greater percentage of married women is suffering in silence and only few reported their encounter.

As observed by Russell, women find it difficult to report the irrational sexual acts of their husband due to their loyalty to them and the family, unwillingness to accept their own victimisation, misunderstandings about a woman's role and marital responsibilities, sexual inexperience about uncertainty on what constitutes "normal" and "forced" sexual relations and reluctance to label the experience as "sexual assault" [1].

According to Elegbeleye, SVWM could be regarded as an uncomfortable, painful and unwanted sexual act that involve threats, force by a partner to achieve sexual contact [2]. Center for Constitutional Rights perceived SVWM as any unwanted sexual penetration (vaginal, anal or oral) or contact with the genitals that is the result of actual or threatened physical force or when the woman is unable to give affirmative consent [3]. Bowker described sexual violence as a sexual exploitation involving sexual contact [4]. Based on the information gathered by the researcher, in some part of the country, some husbands see it as a kind gesture to coerce their wives into engaging in sexual acts with their visitors.

Studies have shown that some men are fond of demanding for sex three, four, five times in a day, and if refused, the wife will face physical assault from the husband. Such could be battered mercilessly, verbally abused, punched, harmed with sharp objects, their food ignored and some threaten to send them away or look for another wife. As observed by the researcher during a marital counselling section, a woman narrated that her 
husband threaten to "rip out her vagina" with a pair of pliers for refusing his sexual demand the fourth time in a day. He also claims that the woman is good for nothing except to be used as sex instrument because she is a full housewife. This category of wives, often find it difficult to resists sexual violence from their husband unlike women that could take over the house responsibility if the husband refused.

SVWM is an important public health issue due to its negative association with social and health outcome. Wives refusal of their husband's sexual advances could result to serious health problem and profound short and long term impact on physical and mental health problem. According to Campbell and Alford, using a nationally representative sample to study rape in America, they found that women that experienced sexual violence by husbands were likely to sustain physical injury [5]. Pagelow found that among 110 battered women, $38 \%$ suffered pelvic pain [6].

It seems that most of the men that sexually coerce their wife do not care about their health. Bachman and Saltzman found that half of the women sampled had been forced to have sex by their husband when they are ill, almost half were coerced immediately after discharge from the hospital, often after childbirth [7]. Nearly half of the women had been verbally abused, humiliated, physically battered and neglected in most cases, and this could result to illness and damage of the body parts [8]. In some cases, husbands could neglect their duties owing to their wives refusal to their sexual demand, such as non-payment of the children school fees, and many other domestic responsibilities which women could find difficult to shoulder alone especially those that are full housewives.

Atimes, some men may vacate the house for days to serve as punishment to the woman as a reaction for her refusal to comply with their sexual desire. As found by Browne, husband neglect usually result to psychological consequences such as anxiety, depression, lack of sleep, eating disorders, lack of interest in sex, fear of men, and other social problems such as drug abuse, suicidal intention and post-traumatic disorder [9].

Women who experience forced sexual acts in intimate relationship seem to be vulnerable to STIs from their partner. It appears that they often find it difficult to negotiate condom use. Using a condom could be interpreted as an admission of promiscuity that could lead to violence from their partner.

The researcher observed that a woman that belongs to the working class seems to enjoy more freedom and respect from their husband when compared with those who are not. This was evident in the report of Jewkes that women that contributes to the upkeep of the family and do not rely solely on the husband, experienced less sexual violent acts from their husband [10]. Moreso, they will not be at home at all times, because they will be busy with their business.

In Nigeria context, marriage is culturally interpreted as granting men the right to unconditional sexual access to their wives. A wife should be subservient to her husband and consensually engaged in sex with him thus making sexual violence not trivial. Women are regarded as part of their husband's properties, a sex object that could be utilized at will.

It appears that men believed in exercising power by using force to achieve their sexual desire. Husband's sexual abnormalities seem to be without prosecution; therefore, they seemed not bothered or sober for their action. It has been observed by the researcher in her interaction with married women during counselling that, wives found it difficult to report their husbands to the law enforcement agents for fear of consequence.

\section{Statement of the Problem}

Sexual Violence within Marriage is frequent and damaging. It is a serious challenge that is making marriage difficult for married women, especially the full housewives. Reports from police, clinical setting, non-governmental organisations and survey research revealed that forced sexual acts occur within marriage to woman of all ages, irrespective of their status, moods and roles at home. The rate of occurrence is alarming.

Greater percentage of women finds it difficult to cope with their husband due to the infliction of sexual problems. Many wives bear the burden of poor health and psychological problems owing to sexual victimization experienced from the husband. It appears some men do not care about the health condition of their wives and probable effects on their children, all they desire from their wives is to exercise power, control, dominance, and derive their maximum sexual pleasure regardless of the outcome of their action thereafter.

As observed by the researcher, these sexual acts of men are becoming unbearable to some married women. These could lead to increased anxiety and distrust emotion for wives and children, creating an unstable environment for all the family members. Homes that are meant to be enjoyed are full of humiliation, threats, depression, self blame, rejection and irrational decisions on the part of either the husband or wife and this could in turn have negative impacts on the entire family. SVWM has now become a matter of concern to guidance counsellors. It is of utmost importance to recognise the damage being done by SVWM. There is need to implement research that will debase further occurrence among married women in Ekiti State Nigeria. 


\section{Purpose of the Study}

The purpose of this study was to investigate the influence of working and full housewives on the sexual violence experienced by married women in Ekiti State. In dealing with the problem of this study and to achieve its purpose, this question is raised to pilot the study.

i. What are the consequences of sexual violence experienced by married women in Ekiti State, Nigeria?

\section{Research Questions}

The following research questions were raised for the study.

i. What are the consequences of sexual violence experienced by married women in Ekiti State?

ii. There is no significant difference in the sexual violence experienced by working and full housewives in Ekiti State.

\section{Methodology}

The study employed descriptive research of the survey type. The design was considered appropriate because it focused on the existing characteristics of a particular group of people in order to resolve their problem. It also involves the distribution of large copies of the instrument used. The population for this study consisted of all married women in EkitiState. The sample consisted of 60 married women randomly selected from six Local Government areas of Ekiti-State, Nigeria.

A research instrument titled "Sexual Violence within Marriage Questionnaire (SCQ)" was used. The instrument was in two sections. Section one sought information on the bio-data of the married women such as age, religion, educational status, employment status, age of marriage, number of children and so on. Section two contains items on the prevalence of sexual violence experienced by married women and the consequences. Test re-test method was used to establish the reliability of the instrument. The reliability coefficient of 0.75 was obtained. The administration of the instrument was done by the principal investigator assisted by some research assistants.

The data generated were analysed using descriptive and inferential statistics. Frequency counts and percentages were used to ensure the general question. T-test was used to test the hypothesis generated. The hypothesis is tested at 0.05 level of significance.

\section{Data Analysis}

General Question 1: What are the consequences of sexual violence experienced by married women in Ekiti State?

Table 1. The Consequences of Sexual Violence Experienced by Married in Ekiti-State

\begin{tabular}{|l|l|l|l|l|l|}
\hline S/N & ITEMS & \multicolumn{2}{l|}{ YES } & \multicolumn{2}{l|}{ NO } \\
\cline { 3 - 5 } & & $\mathrm{N}$ & $\%$ & $\mathrm{~N}$ & \multicolumn{2}{l|}{$\%$} \\
\hline 1. & Communication seize in my marriage & 29 & 48.3 & 31 & 51.7 \\
\hline 2. & $\begin{array}{l}\text { My husband infected with sexually transmitted } \\
\text { infection }\end{array}$ & 21 & 35.0 & 39 & 65 \\
\hline 3. & My husband packed out of the house & 21 & 35.0 & 39 & 65.0 \\
\hline 4. & He doesn't care about my health when in need of sex & 27 & 45.0 & 33 & 55 \\
\hline 5. & I suffer financial support. & 27 & 45 & 33 & 55 \\
\hline 6. & My husband use to transfer aggression to my children & 30 & 50 & 30 & 50 \\
\hline 7. & My husband diverted to extra-marital affairs & 29 & 48.3 & 31 & 51.7 \\
\hline 8. & I was neglected by my husband & 24 & 40 & 36 & 60 \\
\hline 9. & I suffer bruises from my husband & 23 & 38.3 & 37 & 61.7 \\
\hline 10. & My husband used to ignore my food & 22 & 36.7 & 38 & 63.3 \\
\hline
\end{tabular}

In Table $1,48.3 \%$ of the sample reported that the communication seize in their marriage due to failure to meet their husband's sexual desire. $35 \%$ indicated that their husbands have been infected with STIs. Other consequences of sexual violence include: husband packing out of the house $(35 \%)$ 
neglect of spouse (50\%), involvement in extramarital affairs $(48 \%)$, sustained bruises injury $(38 \%)$, and ignoring food $(36.7 \%)$.

Research Question 1: There is no significant difference in the sexual violence experienced by working and full housewives in Ekiti State.

Table 2. T-Test Showing Sexual Violence Experienced by Working and Full Housewives in Ekiti State

\begin{tabular}{|l|l|l|l|l|l|l|}
\hline Groups & $\mathrm{N}$ & Mean & SD & df & t & P \\
\hline $\begin{array}{l}\text { Working } \\
\text { Class }\end{array}$ & 35 & 14.40 & 2.97 & 58 & 3.38 & $<$ \\
\cline { 1 - 3 } $\begin{array}{l}\text { Full } \\
\text { Housewife }\end{array}$ & 25 & 17.16 & 3.31 & & & \\
\hline \begin{tabular}{l} 
P $<0.05$ \\
\hline
\end{tabular}
\end{tabular}

The result in Table 5 reveals that there is significant difference in the sexual violence experienced by working and full housewives in Ekiti State $(\mathrm{t}=3.381, \mathrm{P}<0.05)$. The null hypothesis is rejected.

\section{Discussion of Results}

The result of the study shows that married women suffer tremendous consequences if they refused their husbands' sexual demand. This result was in line with Browne, he opined that wives resistance to their husbands' sexual advancement could result to serious public health problem and profound short and long term impact on the physical and mental health of all the members of the family [9]. It can cause an increased risk of STIs.

The result also revealed that there is significant difference in the sexual violence experienced by working and full housewives in Ekiti State. This result corroborate with the opinion of Jewkes who asserted that housewives that are working will not nurse any fear concerning how they will care for their children without the support of their husband [10]. Moreso, another possible reason for the significant difference is that for the fact that a woman is able to contribute to the house-keeping, this will earn her more respect from the husband.

\section{Conclusion and Recommendation}

It is concluded that victims of SVWM suffer severe verbal abuse, physical injuries with psychological and physical outcomes from their husband that usually resulted to health consequence for all members of the family. It is also concluded that working housewives experienced less sexual violence when compared with full housewives.
Based on the findings of this study and the conclusion drawn, the following recommendations were made.

i. Adequate provision should be made available to woman who had experienced SVWM and their children.

ii. People should have the knowledge that SVWM is a crime that could be prosecuted.

iii. Full housewives should make sure they engage in a kind of work that will improve their status and reduce their staying at home, to avoid incessant sexual demands from their husband.

iv. Ekiti State Government should abolish marital violence exception and establish sexual offence code with penalty.

\section{References}

[1] Russell, D.E.H. (1990). Rape in Marriage. Indianapolis, IN: Indiana University Press.

[2] Elegbeleye, O.S. (2006). Is rape in the eye or in the mind of the offender? A survey of rape perception and Nigeria University stakeholders. Depertment of Psychology, Obafemi Awolowo University, IIe-Ife. Email: TOBAEZ@yahoo.com, tobael@ oauife.ed.ng. Education Research and Review Vol 1, pp. 40-51.

[3] Center for Constitutional Rights (1990). Stopping sexual assault in marriages: A guide for women, counsellors, and advocates (2nd ed). New York: Center for Constitutional Rights.

[4] Bowker, L.H. (1983). Marital rape: A distinct syndrome? Social Casework, 347-352.

[5] Campbell, J.C., and Alford, P. (1989). The dark consequences of marital rape. American Journal of Nursing, 946-949.

[6] Pagelow, M.D. (1981). Family Violence. New York: Praeger.

[7] Bachman, R. and Saltzman, L.E. (1995). Violence againstwomen: Estimates from the redesigned survey (BJS Publication No. 154-348). Washington, DC: U.S. Departmental of Justice, Bureau of Justice Statistics.

[8] Kilpatric, D.G., Best, C.L., Saunders, B.E. and Veronen, L.J. (1988). Rape in marriage and in dating relationships: How bad is it for mental health? In R. A. Prentky \& V. L. Quinsey (Eds.), Human Sexual Aggression: Current Perspectives (pp. 335-344). New York: New York Academy of Sciences.

[9] Browne, A. (1993). Violence against women by male partners: Prevalence, outcomes, and policy implications. American Psychology, 48(10), 1077-1087. 10.

[10] Jewkes, R. (2002). "Intimate partner violence: causes and prevention". Lancet 339 (9315):1423-1429. Doi: $\quad 10.1016 /$ sos140-6736(02) 080357-5. PMID 11978358 . 